\title{
PRESUMPTION OF INNOCENCE AND DETERRENCE
}

MARIE OBIDZINSKI, YvES OYTANA

\section{www.tepp.eu}

TEPP - Institute for Labor Studies and Public Policies TEPP - Travail, Emploi et Politiques Publiques - FR CNRS 3435 
ISSN 2110-5472 


\title{
Presumption of innocence and deterrence
}

\author{
Marie Obidzinski* Yves Oytana ${ }^{\dagger}$
}

February 3, 2018

\begin{abstract}
This paper deals with the presumption of innocence and the law enforcer's incentives to exert investigative effort. Our main result is that, even if the presumption of guilt maximizes deterrence for a given effort by the law enforcer, divergent objectives between the law enforcer (who maximizes the probability of a conviction weighted by the magnitude of the sanction and the type of the citizen) and the public decision-maker (who minimizes social costs) may lead the latter to prefer the presumption of innocence. Indeed, the presumption of innocence may induce the law enforcer to increase investigative efforts thereby improving deterrence. As a consequence, if the law enforcer's effort is relatively efficient compared with its cost, and if the external harm from the crime is high enough, considering the law enforcer's effort as an endogenous variable tilts the balance in favor of the presumption of innocence. Therefore, under some conditions, the presumption of innocence does not interfere with deterrence.
\end{abstract}

Keywords: Evidence acquisition, presumption of innocence, standard of proof, deterrence.

JEL codes: K4.

*CRED (TEPP), Université Paris II Panthéon-Assas, 12, place du Panthéon, 75005 Paris, France.

†CRESE EA 3190, Université Bourgogne Franche-Comté, F-25000 Besançon, France. e-mail: marie.obidzinski@u-paris2.fr, yves.oytana@univ-fcomte.fr We are grateful to participants at the second conference of the French Association of Law and Economics (AFED) and at the 2017 European Association of Law and Economics (EALE) for their insightful comments. All errors remain our own. 


\section{Introduction}

Motivation. A standard criticism of the public law enforcement literature is that it fails to take into account the strategic behavior of criminal law enforcement agents (Friedman, 1992; Gordon and Huber, 2009; Dharmapala et al., 2016). ${ }^{1}$ However, the objectives of citizens and criminal law enforcers are not necessarily perfectly aligned. Criminal law enforces are not inanimate objects but strategic actors. Hence, there is no doubt that their strategic behavior and the resulting decisions they make should be taken into account when analyzing optimal public law enforcement policy. This is of particular importance when it comes to legal errors, since the strategic decisions of the investigating agents can affect law enforcement through accuracy.

Indeed, both investigating agents' efforts and criminal procedure rules affect the occurrence of legal errors (the investigating agents are those who collect evidence, such as the police department or the prosecution service). First, regarding the investigating agents' efforts, more effort may enhance accuracy and may therefore reduce both the probability of a wrongful conviction and the risk of a false acquittal (Kaplow and Shavell, 1994). ${ }^{2}$ Second, criminal procedure rules may place the burden of proving the culpability of the suspect on the prosecutor (through the presumption of innocence), or may require a high degree of certainty to find the defendant guilty (through the standard of proof, such as "beyond any reasonable doubt").

Criminal procedure rules and the investigating agent's effort should not be considered independently. Indeed, rules of procedure may greatly affect the incentives of investigating agents. More specifically, the two relate in the following way: the quality/quantity of investigations depends on the resources (personal or not) devoted to investigative effort;

\footnotetext{
${ }^{1}$ Indeed, as explained by Friedman (1992), "expanding the [standard model à la Becker] to take account of the incentives of the enforcers makes the problem of optimal punishment more difficult", but it "also provides explanations for features of our legal institutions that seem puzzling under the traditional analysis." However, such analysis are scarce in the literature, with the exception of rentseeking (Garoupa and Klerman, 2002), corruption (Bowles and Garoupa, 1997), or electoral concerns (Langlais and Obidzinski (2017)), and the issue of effort has rarely been addressed (to the recent exception of Dharmapala et al., 2016).

${ }^{2}$ By false acquittals, we also have in mind the closing of legal proceedings in the absence of enough evidence. For instance, more effort from the police, or from the prosecutor might lead to less closing.
} 
the choice of this level of effort might depend on its marginal impact on the probability of securing a conviction and sanction; and this marginal impact depends, in turn, on the rules of procedure (Stephenson, 2011; Kahn et al., 2017). However, the rules of procedure and the investigating agent's effort are determined at different stages. Rules of procedure, such as the principle of the presumption of innocence, are defined ex ante by the public authority (Parliament), and applied at the end of the legal procedure when the court makes its decision. In contrast, the investigating agent chooses his level of effort when collecting evidence ex post, in the shadow of these rules of procedure.

This has important consequences on deterrence issues. Indeed, complaints are often heard that rules of procedure undermine deterrence. If this is true, then the deterrence objective of criminal law might interfere with the pro-defendant bias in criminal procedure, and so provide grounds for questioning the presumption of innocence (Tadros, 2007). This is what our paper is about: Does the presumption of innocence reduce deterrence when the law enforcer's effort is endogenous? To investigate this question, we consider a framework in which a public authority could adopt the principle of the presumption of either innocence or guilt. Under the former (latter), the innocence (culpability) of the defendant is the null hypothesis, and the alternative hypothesis that the defendant is guilty (innocent) may prevail only if the law enforcer finds enough incriminating (exculpatory) evidence.

While the presumption of guilt might be perceived as theoretical and quite unrealistic, we believe it is helpful to consider this antagonist case in order to understand on what grounds the principle of the presumption of innocence may be justified. Moreover, there are situations in which the presumption of guilt is applied. Let us consider two examples. The first relates to pretrial detention, the practice of incarcerating individuals with the aim of preventing them from committing offenses. This may conflict with the principle of the presumption of innocence. Indeed, Kitai-Sangero (2009) argues that "detention for the purpose of preventing the commission of further offenses inherently undermines the presumption of innocence" and claims that "the argument that a danger exists that the detainee will commit further offenses reflects a presumption of guilt and a negative appraisal of his character." The second example relates to the low standard of proof ob- 
served in substantiation of child abuse and neglect. Indeed, Levine (1998) explains that "some states use a lower standard of proof of some credible evidence (or similar terms) to substantiate cases after investigation", while other states prescribe a higher standard of "preponderance" of the evidence. With a standard of "some credible evidence", the court may decide to substantiate allegations of abuse and neglect even if its belief that these allegations are true is lower than $50 \%$, implying possibly a presumption of guilt. ${ }^{3}$

Furthermore, the notion of the presumption of innocence (or guilt) is closely related to the concept of standard of proof (or burden of proof), the standard of proof referring to the degree of certainty required for the court to convict a suspect. Both notions relate to the strength of evidence needed to convict. It is probable that stronger evidence will be required to secure a conviction if there is a presumption of innocence or a high standard of proof, such as the "beyond any reasonable doubt" or "intime conviction". On the contrary, the presumption of guilt can be compared to a low standard of proof such as the "preponderance of evidence" where weak evidence may be sufficient to secure a conviction.

Contribution. The law and economics literature on the relation between presumption of innocence in criminal procedure is scarce if not non-existent. However, the presumption of innocence is a component of the observed pro-defendant bias in criminal law, as is the high standard of proof. Indeed, and quite paradoxically, the high standards of proof observed in criminal law (such as "beyond any reasonable doubt" or "intime conviction") are hardly (if at all) explained by deterrence (Png, 1986; Rizzolli and Saraceno, 2013). Some rational explanations for a high standard have been given in the law and economics literature, such as the higher relative cost of wrongful convictions compared to wrongful acquittals (Miceli, 1990; Miceli, 1991; Lando, 2009), the risk of chilling desirable behavior under a low standard of proof (Kaplow 2011a,b), the attitude toward risk of potential criminals and various behavioral biases (Nicita and Rizzolli, 2014), the high cost of the penalty in criminal cases (Rizzolli and Saraceno, 2013), the victim's incentive to invest in precaution and tortfeasor's incentive to invest in precautionary effort (Mungan, 2011),

\footnotetext{
${ }^{3}$ See also Kahn et al. (2017) on the subject of child substantiation.
} 
or the risk of mistakes as to identity (Obidzinski and Oytana, 2017). The explanation in our paper rests on the nature of the criminal procedure, in which the investigations are largely delegated. The public authority can use rules of procedure in order to provide the right incentives to the law enforcer, leading to greater accuracy.

Assumptions and main results. We present a very stylized model in which a citizen (who may be innocent or guilty) may be suspected of a crime; if detected, a law enforcer (prosecutor) is in charge of investigating the case by making (or not) a costly effort to obtain evidence. This evidence may be incriminating, exculpatory, or uninformative. If the evidence obtained is uninformative, the court's decision depends on the null hypothesis: the citizen is acquitted if the principle of the presumption of innocence is applied, and is otherwise sentenced (i.e. if the principle of the presumption of guilt is applied).

Our main results are the following. Assuming the law enforcer's objective is to maximize the expected punishment (eventually weighted by the defendant's type) minus the cost of his effort, he may choose a high level of effort if and only if there is a presumption of innocence. Also, for a given level of effort by the law enforcer, the presumption of guilt induces higher deterrence. This is no longer the case when the law enforcer chooses his investigative effort. Thus, for the policymaker, adopting the presumption of innocence may be a way to incentivize the law enforcer to choose a high level of effort, and thus to potentially increase deterrence as a side effect. This is our main result. In an extension, we show that this result holds even if the law enforcer is averse to type 1 errors, as long as that aversion is not too great when compared to his aversion to type 2 errors. We also discuss the optimal sanction. We find that deterrence increases with the level of the sanction (which is consistent with the standard result of Becker, 1968), even if, interestingly, increasing the sanction may reduce the law enforcer's incentive to exert high effort. Moreover, we show that, when the sanction increases, adopting the presumption of innocence may be more or less desirable, depending mainly on the initial level of the sanction.

Obviously, deterrence is not the only goal pursued by the policymaker, who is a social 
surplus maximizer and thus also cares about the cost of the procedure. As a consequence, a higher effort from the law enforcer is not always beneficial. More specifically, even when the law enforcer's effort is higher under the principle of the presumption of innocence, the policymaker's choice whether to apply this principle depends on the magnitude of the external harm if a crime is committed, and on the relative fact-finding efficiency of the law enforcer's effort when compared to the cost of his effort. Presumption of innocence tends to be more beneficial when the external harm and the efficiency of the law enforcer's effort increases, and the cost of this effort decreases.

Summary of the paper. The rest of this paper is organized as follows. We introduce some of the related literature in section 2 . In section 3 , we present the model and solve it. In section 4, we derive the conditions under which the presumption of innocence should be adopted, and formulate public policy recommendations. Section 5 is an extension in which we assume that the law enforcer is averse to both type 1 and type 2 errors. Finally, section 6 concludes.

\section{Literature}

Our paper is related to two main strands of literature. The first one analyzes the law enforcer's motivations. The second one investigates the rules of evidence.

First, the public enforcement literature has mostly ignored the law enforcer's motivations. There are a few exceptions. Friedman (1999)'s well-known paper notes that law enforcers are not inanimate objects and might try to extract rents from citizens by threatening them with excessive punishment. To limit this power of law enforcers, society promotes inefficient punishments such as imprisonment. ${ }^{4}$ Costly punishment guards against rentseeking-behavior. Hylton and Khanna (2007) use a public choice approach to justify the pro-defendant bias in criminal procedure. They also focus on rent-seeking issues. Besides this literature on rent-seeking, there is extensive literature on corruption, starting with Becker and Stigler (1974). Our paper differs in the sense that we are not interested in

\footnotetext{
${ }^{4}$ See Wickelgren (2003) who models this hypothesis by Friedman (1999).
} 
the extraction of rent or bribes by the law enforcer, but mainly in his strategic decision about effort when he is self-interested.

There is also a growing literature on law enforcers, and more specifically on prosecutors. According to Gordon and Huber (2009), two extreme views of the prosecutor are to be found in the literature. One assumes that the prosecutor aims at minimizing type 1 and type 2 errors and promoting justice while limiting resources spent on enforcement (for instance, Reinganum, 1988). The second view, on the contrary, assumes that the prosecutor is (only) looking for harsh sentences and high conviction rates (see for instance Landes, 1971; Miceli, 1990; Bar-Gill and Ayal, 2006). A third, middle-of-the-road view is emerging, assuming that the prosecutor is trading off between these two views and personal and career concerns (Gordon and Huber, 2009; Shotts and Wiseman, 2010). Our paper is more in line with the last view, since we assume that the prosecutor might have some preferences over limiting type 1 /type 2 errors, as well as securing convictions (weighted by the magnitude of the sanction), but that investigating effort is costly. More recently, Dharmapala et al. (2016) investigate the principal-agent relationship between society and investigating agents. Individuals with a preference for punishing wrongdoers self-select into law enforcement jobs. It is cheaper for society to employ such individuals since they will accept lower wages and are more likely to make an effort. However, society should monitor the work of these employees, through the judiciary. Our idea is similar, since we focus on how the presumption of innocence can influence the effort made by law enforcers. We do not use the notion of "intrinsic" preferences but allow enforcers to attribute different weights to legal errors, and to have a preference for punishing wrongdoers.

The effects of the constraints imposed on prosecutors have also been largely studied. For instance, Garoupa (2009) shows that mandatory prosecution may dominate selective prosecution when prosecutors are risk-averse or fairly insulated from their performance. Indeed, mandatory prosecution limits prosecutorial shirking that leads to inefficient selection of cases. Garoupa and Rizzolli (2011) study the mandatory revelation of evidence found by the prosecutor (the so-called Brady Rule) and explain that this rule may harm innocent defendants by disincentivizing the prosecutor to search for new evidence, in 
order to avoid finding exculpatory evidence. Like these models, we show that the law enforcer's effort at the equilibrium does not generally fit the first best level of effort because (i) the goals of the law enforcer are not perfectly aligned with those of society and (ii) the law enforcer's choice of effort occurs ex post, that is after the act has been committed (on this subject, see Stephenson, 2011; Kaplow, 1994). However, we do not deal with the prosecutor's selection of cases and with the strategic revelation of information, in order to focus instead on the optimal presumption, assuming that prosecution is mandatory and that all the evidence gathered is observable by the court. This last assumption may be justified on the ground that withholding evidence is risky for the prosecutor. Indeed, as explained by Gordon and Huber (2002) (who use the same assumption), "[withholding evidence] is a highly risky strategy. The prosecutor might lose at trial should the defense access the withheld information by other means or suffer the humiliation of a dismissal if the suppression is detected."

The literature based on empirical evidence is extensive when it comes to the prosecutor's preferences. Let us quote three papers. McCannon (2013) shows that when the prosecutor is running for reelection, the probability of wrongful convictions increases significantly. Therefore, future electoral prospects affect prosecutors' decisions. Glaeser et al. (2000) focus on prosecutors' choices in the United States to allocate cases at the federal level or at the state level, and tries to infer from these decisions the motivations of prosecutors. Finally, and in line with our assumptions regarding the prosecutor's preferences, Boylan (2005) shows that the career of U.S. federal (appointed) prosecutors is positively associated with the length of prison sentences, rather than with conviction rates.

Second, there is extensive literature on the rules of evidence, and particularly on the effect of the standard of proof and the burden of proof on decision-making in court and ex ante incentives of parties (see among other Emons and Fluet, 2009; Shin, 1994; Hay and Spier, 1997). However, this literature mainly focuses on civil cases and compares the merits of adversarial and inquisitorial systems. Deffains and Demougin (2008) focus on the investigative effort of the parties and/or prosecution in the context of an inquisitorial (like the one used in France) versus an adversarial procedure (like the one used in the 
United States) in a criminal court setting. They find that, depending mainly on the distribution of wealth of defendants, an inquisitorial procedure may dominate an adversarial procedure, because the policymaker is more able to influence the parties' expenditures in the former, despite the higher cost of investigative effort for given levels of these efforts (due to the social cost of public funds used to finance prosecution). Rubinfeld and Sappington (1987) analyze a game in which a defendant (who knows if he is guilty or not) makes a costly effort to influence a decision-maker, whose objective is to minimize the sum of the social cost of type 1 and type 2 errors and the defendant's costs. To do this, the decision-maker may act with respect to the standard of proof and the magnitude of the sanction. In contrast to these papers, we consider a procedure where the investigative effort is centralized by an investigating agent with misaligned preferences from those of the policymaker, and who is influenced by the principle of presumption applied. However, the principle of presumption is closely related to the burden of proof and the standard of proof.

Two papers are particularly close to the present one. The first one is Stephenson (2008), which introduces a game between an agent and a decision-maker who pursue different objectives. In this game, the agent is informed about the true state of the world and chooses to make a low or high effort to obtain evidence observable by the decision-maker. The main differences with our paper are that we assume the agent (the law enforcer) is not informed about the state of the world, and that we are interested in the level of deterrence. The second closely related paper is Garoupa (2018), who shows that the high standard of proof used in criminal law may be explained by the law enforcer having punitive preferences (this model builds on Dharmapala et al., 2016). However, the channel through which this high standard is explained is different from ours. Indeed, Garoupa (2018) focuses on the transmission of information by the prosecutor, who communicates to the court a probability of the citizen being guilty. Distorting this probability is costly for the prosecutor. Thus, for the policymaker, a higher standard of proof raises the cost incurred by the prosecutor of distorting evidence sufficiently to ensure a conviction, and thus reduces the probability of him deciding to do so. In contrast, we focus on the impact of the presumption of innocence on the law enforcer's incentive to search for evidence, 
assuming that it is impossible to distort evidence. ${ }^{5}$ Moreover in our paper, we focus on the cost of type 1 and type 2 errors through deterrence, whereas the cost of these errors is exogenous in Garoupa (2018). However, we believe that our approach is complementary to that of Garoupa (2018): both models provide different explanations for the pro-defendant bias in criminal law, and the two explanations arise from the assumption that the law enforcer has punitive preferences.

\section{The model}

Model description. There are three players: a policymaker, a citizen, and a law enforcer (prosecutor). The policymaker's objective is to minimize the expected external harm and the effort cost. He initially chooses either the presumption of guilt (regime 1) or innocence (regime 2) and the sanction. The citizen (she) decides whether or not to commit a crime. Her payoff is her benefit from the crime (if she commits a crime) minus the expected punishment cost. The law enforcer (he) chooses his investigative level of effort in order to maximize the probability of conviction (weighted by the sanction and the citizen's type $)^{6}$ minus the cost of his effort.

The timing of the game is the following:

$\mathbf{t}=\mathbf{0}$. The policymaker chooses the presumption of guilt or innocence and the level of the sanction.

$\mathbf{t}=\mathbf{1}$. Nature chooses the magnitude of the private benefit obtained by the citizen if she chooses to commit a crime.

$\mathbf{t}=\mathbf{2}$. The citizen decides whether or not to commit a crime.

$\mathbf{t}=3$. Nature decides whether or not a case is brought against the citizen (the probability of a case being brought is lower if the citizen did not commit any crime). If not, the game ends.

\footnotetext{
${ }^{5}$ As a consequence, the beliefs held by the court and the law enforcer are always the same in our model.

${ }^{6}$ The citizen's type refers here to whether she has committed a crime (i.e. whether she is guilty or innocent).
} 
$\mathbf{t}=4$. If a case is brought against the citizen, the law enforcer chooses his level of effort, resulting in a signal (which may be uninformative) about the citizen's decision to commit a crime or not.

$\mathbf{t}=\mathbf{5}$. Depending on the presumption of innocence/guilt and the signal observed by the court, the sanction is applied and payoffs are realized. ${ }^{7}$

The equilibrium concept is perfect Bayesian equilibrium (PBE). This implies that each player maximizes their expected payoff (we assume risk neutrality) and that their beliefs must be consistent at the equilibrium.

\subsection{The criminal law enforcer's effort}

What are the motivations of law enforcers in criminal law? Somehow, law enforcers (such as prosecutors or police officers) seem to be torn between (i) the objective of justice (punishing wrongdoers while avoiding convicting innocent individuals) and (ii) more prosaic career concerns. ${ }^{8}$ The first motive comes from a (closed) view of criminal law enforcers according to which they are "intrinsically motivated to punish wrongdoers" (Dharmapala et al., 2016). ${ }^{9}$ Regarding the second motive, reputation matters both when the prosecutor is elected or when he is appointed. Since the law enforcer's effort is difficult to observe, the rate of convictions and the magnitude of sanctions serve as a proxy to limit the adverse effects of moral hazard (see for example the work of Landes, 1971; Easterbrook, 1983; Gordon and Huber, 2002).

In our model, we assume the law enforcer (prosecutor) maximizes a weighted probability

\footnotetext{
${ }^{7}$ Implicitly, we assume that the law enforcer does not hide the evidence acquired through his investigations. This hypothesis can be justified in many ways. First, the imposition of a presumption of innocence/guilt implies that the judge can observe the evidence produced by the law enforcer, as in Stephenson (2011). Second, the issue of hiding evidence might not be central. Indeed, as explained by Gordon and Huber (2002), withholding evidence is a risky strategy since "the prosecutor could face charges of suborning perjury or obstructing justice and could be disbarred for ethics violations." Third, even if the prosecutor can conceal evidence, our results still hold if there is a positive probability that the concealed evidence may leak (albeit our results may be weakened in this case).

${ }^{8}$ See for instance Gordon and Huber (2009) for a discussion of the prosecutor preferences, as well as Lemos and Minzner (2014).

${ }^{9}$ As Dharmapala et al. (2016) note: "The fact that the job of police and prosecutors is mostly about facilitating criminal punishment means that they will be more intensely motivated by such policy and [...] more punishment-preferring than the median voter."
} 
of conviction, minus the cost of his effort. Formally, the law enforcer obtains a gain normalized to $s>0$ if a guilty defendant is convicted at trial (with $s$ the sanction initially chosen by the policymaker), a gain of $V s$ if an innocent defendant is convicted (with $V \leq 1$ ), and incurs a cost of $w s$ when he fails to convict a guilty defendant (with $w \geq 0$ ). ${ }^{10}$ According to these assumptions (summarized below in table 1), the law enforcer's utility from convicting a guilty defendant is higher or equivalent to his utility from convicting an innocent defendant, and he suffers a loss if he fails to convict a guilty defendant.

The law enforcer's prior probability according to which the defendant is guilty is given by $\alpha \in(0,1)$. This probability is an endogenous variable of the model. As such, it will be determined later.

\begin{tabular}{|c|c|c|c|}
\hline \multirow{2}{*}{ Suspect is: } & Law enforcer's & \multicolumn{2}{|c|}{ Utility } \\
\cline { 3 - 4 } & prior belief & Convict & Acquit \\
\hline Guilty & $\alpha$ & $s$ & $-w s$ \\
\hline Innocent & $1-\alpha$ & $V s$ & 0 \\
\hline
\end{tabular}

[Table 1: The law enforcer's preferences]

The law enforcer revises his prior belief $(\alpha)$ after observing a signal (which may be either perfectly informative or uninformative) about the citizen's choice whether to commit a crime. The quality of this signal (i.e. the probability of it being informative) depends on the law enforcer's effort. Formally, the law enforcer obtains strong evidence with probability $q_{h}\left(q_{l}\right)$ if he exerts high effort (if he exerts low effort), with $0<q_{l}<q_{h}<1$. $^{11}$

\footnotetext{
${ }^{10}$ These payoffs are very similar to the one specified in Garoupa and Rizzolli (2011). For example, if $V=1$ and $w=0$, then the law enforcer cares only about maximizing the number of convictions (punitive law enforcer), while if $V=0$ and $w=0$, the law enforcer wishes to convict the defendant only if he is guilty (benevolent law enforcer). Differences with Garoupa and Rizzolli (2011) are that we do not consider the possibility of the law enforcer dropping a case (i.e. we assume that mandatory prosecution applies), and that the law enforcer's gains from convicting an innocent person or a criminal are weighted by the sanction. However, it is easy to show that our main results regarding the optimal presumption remain qualitatively the same if the law enforcer's gains from a conviction are not weighted by $s$.

${ }^{11} \mathrm{We}$ assume that the law enforcer's effort does not affect the level of the sanction.
} 
The cost incurred by the law enforcer when he exerts high effort is $k>0$. We normalize the cost of effort to 0 if he chooses low effort.

To summarize (see figure 1), when the law enforcer chooses his level of effort, he anticipates that he will obtain (i) strong evidence of the citizen's guilt with probability $\alpha q$, with $q \in\left\{q_{l}, q_{h}\right\}$, (ii) strong evidence that the citizen did not commit the crime with probability $(1-\alpha) q$, and (iii) inconclusive evidence with probability $(1-q)$.

The law enforcer's expected payoff depends on the rules of procedure, and there are two relevant alternatives in our model; the presumption of innocence and the presumption of guilt. To understand why, we need to consider in turn (i) the case in which the court observes strong evidence, and (ii) the case in which evidence is inconclusive. First, if the court observes strong evidence that the citizen is guilty (innocent), then the court convicts her (acquits her), since the signal is perfectly informative. This is, of course, a simplification, implying that no error is made if the evidence is conclusive. Second, if the evidence is inconclusive, the decision made by the court depends on the presumption applied. Under the presumption of innocence, inconclusive evidence is not sufficient to convict the citizen, who is acquitted as a consequence. In this case, the probability of a type 2 error is (strictly) positive (a guilty defendant may be acquitted). Conversely, under the presumption of guilt and inconclusive evidence, the court will decide to convict the citizen. In this case, the probability of type 1 error is (strictly) positive (an innocent defendant may be convicted). ${ }^{12}$ These assumptions are summarized in figure 1.

\footnotetext{
${ }^{12}$ Type 1 and type 2 errors refer here to ex post errors: we do not refer to errors in detection, but only to errors in convictions. We will later refer to both errors in detection and in conviction, for example to comment on equations (9) and (12).
} 


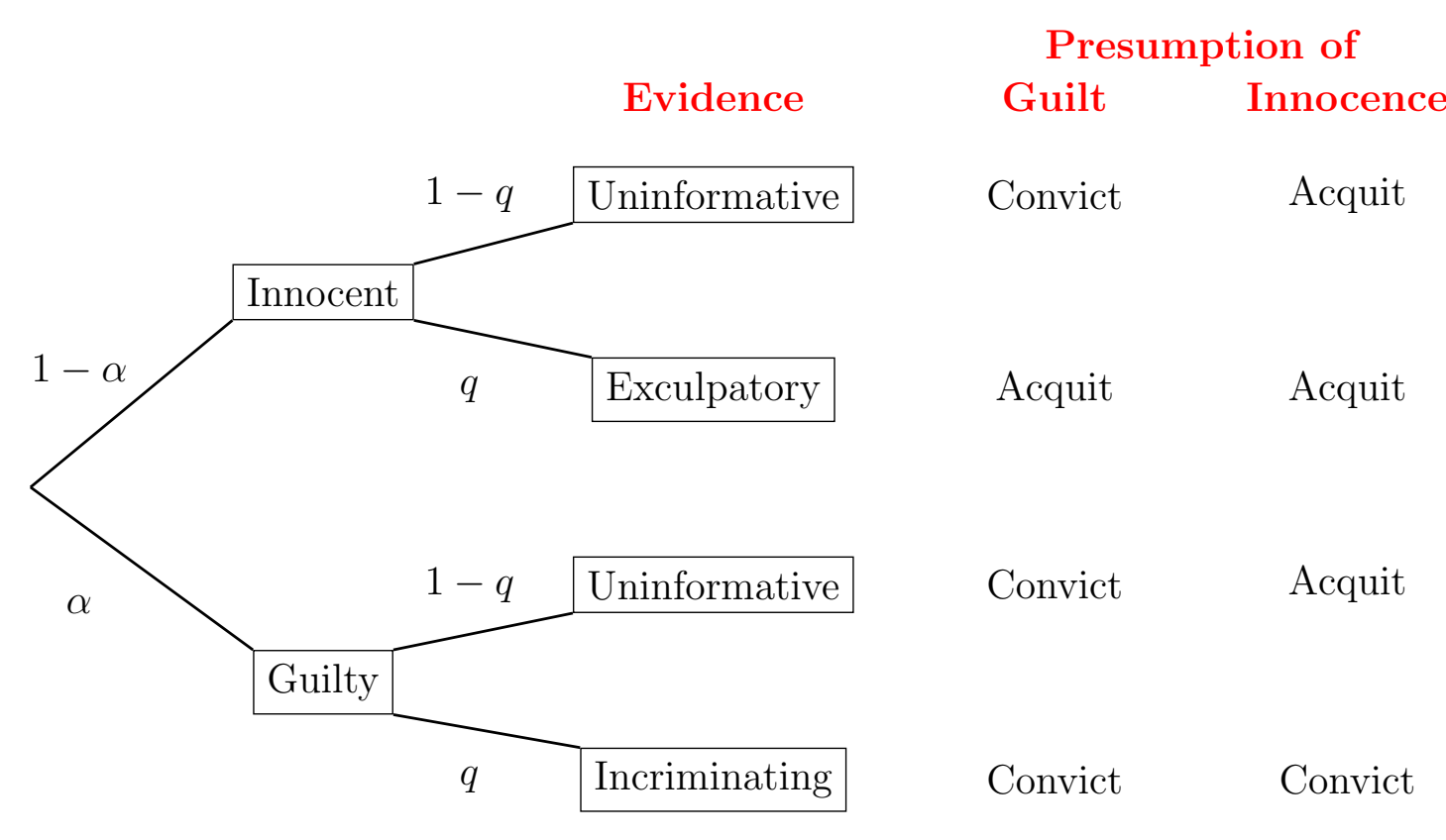

[Figure 1: Evidence found by the law enforcer and the court's decision]

Two important remarks are in order here. First, the assumption according to which, under the presumption of guilt, the court convicts the citizen when the law enforcer gathers uninformative evidence, may seem very strong. However, in the context of our model, obtaining uninformative evidence does not mean that the posterior probability that the citizen is guilty is less than $1 / 2$ (and thus does not satisfy even a preponderance of evidence standard). Indeed, when the court makes a decision, the judge's posterior belief not only depends on the evidence obtained by the law enforcer, but also on the crime rate at equilibrium and the probability of detection (which we assume is higher for a citizen who has committed a crime). Thus, even if the evidence gathered by the law enforcer is uninformative, the judge's belief that the citizen is guilty may be quite strong under the presumption of guilt, justifying a conviction. This situation is illustrated later in example 1. Second, we implicitly assume, for simplicity, that it is impossible to find incriminating (exculpatory) evidence against an innocent (guilty) party. If not, the analysis would be much more complicated, but our main results would remain qualitatively unchanged as long as the probabilities of finding such evidence are not too high. 
What is the law enforcer's level of effort under the presumption of guilt (regime 1)? As explained above, under the presumption of guilt, a citizen is always convicted when detected, except if strong evidence that the citizen did not commit a crime is observed by the court. The law enforcer's payoff if he exerts low effort is:

$$
u_{1, l}^{p}=\left[\alpha+(1-\alpha)\left(1-q_{l}\right) V\right] s
$$

We use the subscript 1 (2) to indicate the presumption of guilt (innocence), and the subscript $l(h)$ to indicate that the law enforcer's effort is low (respectively high). For example, $u_{1, h}^{p}$ is the law enforcer's payoff (the superscript $p$ is for "prosecutor") under the presumption of guilt, when his effort is high.

If the law enforcer exerts high effort, the probability of him obtaining exculpatory evidence when the citizen is innocent increases. His payoff is:

$$
u_{1, h}^{p}=\left[\alpha+(1-\alpha)\left(1-q_{h}\right) V\right] s-k
$$

Under the presumption of guilt, the law enforcer (strictly) prefers to exert high effort if and only if $u_{1, h}^{p}>u_{1, l}^{p}$, which is equivalent to:

$$
k<-(1-\alpha) \Delta q V s:=k_{1}
$$

with $\Delta q=q_{h}-q_{l}$. Note that if $V \geq 0$ (i.e. the law enforcer obtains a positive gain when an innocent party is convicted), then $k_{1} \leq 0$ : the law enforcer always chooses low effort under the presumption of guilt. In the following, we assume that $V \geq 0 .{ }^{13}$ Even if $V=0$ (the law enforcer derives no gain from punishing the innocent), the law enforcer chooses the low effort under the presumption of guilt, since the effort does not affect the probability of convicting a guilty individual. We solve the model for $V<0$ in section 4 .

\footnotetext{
${ }^{13}$ This assumption is consistent for example with the model of Bar-Gill and Ayal (2006), in which the law enforcer's utility increases with the length of sentences assigned to defendants (whether or not these defendants are guilty), and encompasses the cases of a benevolent law enforcer $(V=0)$ and of a punitive law enforcer $(V=1)$, as defined earlier in footnote 11 .
} 
What is the law enforcer's level of effort under the presumption of innocence (regime 2)? In this case, the citizen is convicted only if strong evidence that she did commit the crime is observed by the court. The law enforcer's payoff if he exerts low effort is:

$$
u_{2, l}^{p}=\left[\alpha q_{l}-\alpha\left(1-q_{l}\right) w\right] s
$$

If the law enforcer exerts high effort, the probability of him obtaining incriminating evidence when the citizen is guilty increases. His payoff is:

$$
u_{2, h}^{p}=\left[\alpha q_{h}-\alpha\left(1-q_{h}\right) w\right] s-k
$$

Under the presumption of innocence, the law enforcer (strictly) prefers to exert high effort if and only if $u_{2, h}^{p}>u_{2, l}^{p}$, which is equivalent to:

$$
k<\alpha \Delta q(1+w) s:=k_{2}
$$

Note that $k_{2} \geq 0$. More specifically, from condition (6), we find that under the presumption of innocence, the law enforcer exerts high effort if his cost of effort $(k)$ is not too large when compared to his prior that the citizen is guilty $(\alpha)$, the relative efficiency of his effort $(\Delta q)$, the sanction $(s)$ and the weight he gives to failing to convict the guilty $(w)$.

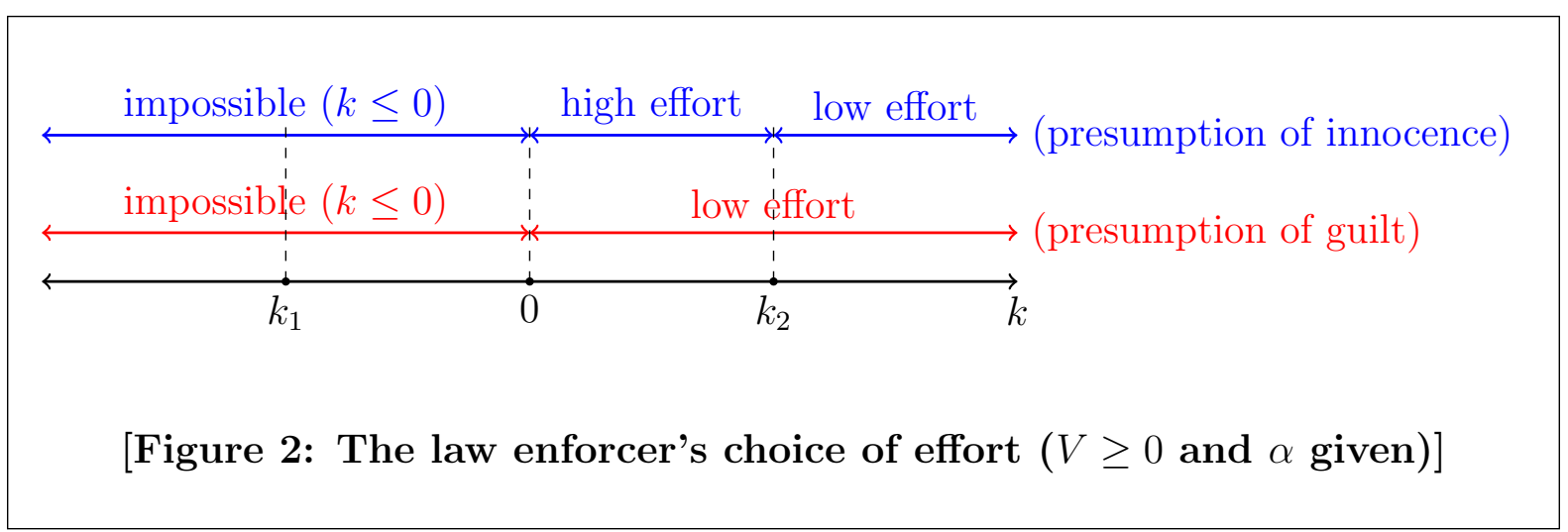




\subsection{Committing crimes under the presumption of innocence or the presumption of guilt}

In the following, we analyze in turn the citizen's decision whether or not to commit a crime (3.2.1) and the impact of the law enforcer's effort on errors and deterrence (3.2.2) under the presumptions of guilt and innocence.

\subsubsection{The citizen's decision to commit a crime}

Citizens differ in the benefit $b$ they get from the crime. This benefit is distributed according to the density function $f$ and the cumulative distribution $F$, as is usual in the literature issuing from Becker (1968). Let us denote by $y$ the initial wealth of the citizen, $p_{g} \in(0,1)$ the probability that she is detected if guilty, and $p_{i} \in\left(0, p_{g}\right)$ the probability that she is detected if innocent, where the subscript $i(g)$ refers to innocence (guilt).

We begin with the citizen's decision under the presumption of guilt. The citizen's payoff $u_{1}^{i}$ if she decides not to commit a crime is:

$$
u_{1}^{i}=y-p_{i}(1-q) s
$$

Conversely, if she decides to commit a crime, her expected payoff is:

$$
u_{1}^{g}=y+b-p_{g} s
$$

Thus, under the presumption of guilt, the citizen will commit a crime if $u_{1}^{g} \geq u_{1}^{i}$, which is equivalent to:

$$
b \geq[1-\underbrace{\left(p_{i}(1-q)\right)}_{\text {Type } 1 \text { error }}-\underbrace{\left(1-p_{g}\right)}_{\text {Type } 2 \text { error }}] s \Leftrightarrow b \geq\left(p_{g}-p_{i}(1-q)\right) s:=\hat{b}_{1}
$$

This condition may be interpreted in light of the standard result of Png (1986): deterrence decreases with respect to both the probability of a type 1 error (which occurs with probability $p_{i}(1-q)$ ) and the probability of a type 2 error (which occurs with probability 
$\left.1-p_{g}\right) \cdot{ }^{14}$

We now focus on the citizen's decision under the presumption of innocence. If the citizen decides not to commit a crime, her payoff is:

$$
u_{2}^{i}=y
$$

Conversely, if she decides to commit a crime, her expected payoff is:

$$
u_{2}^{g}=y+b-p_{g} q s
$$

Thus, under the presumption of innocence, the citizen will commit a crime if $u_{2}^{g} \geq u_{2}^{i}$, which is equivalent to:

$$
b \geq[1-\underbrace{(0)}_{\text {Type } 1 \text { error }}-\underbrace{\left(\left(1-p_{g}\right)+p_{g}(1-q)\right)}_{\text {Type } 2 \text { error }}] s \Leftrightarrow b \geq p_{g} q s:=\hat{b}_{2}
$$

The interpretation of (12) is similar to (9): deterrence decreases with respect to the probabilities of both type 1 and type 2 errors.

Note that, for a given effort by the law enforcer (i.e. by considering $q$ as exogenous), we find a standard result according to which an increase in the pro-defendant bias (in our model, shifting from the presumption of guilt to the presumption of innocence) (i) reduces the probability of a type 1 error and (ii) increases the probability of a type 2 error (see for example Rizzolli and Saraceno, 2013). ${ }^{15}$ Also, still for a given effort by the law enforcer, the crime rate is lower under the presumption of guilt since $\hat{b}_{1}>\hat{b}_{2}$, and thus $1-F\left(\hat{b}_{1}\right)<1-F\left(\hat{b}_{2}\right)$. However, this last point may no longer be true if we endogeneize the law enforcer's choice of effort. Indeed, as we will see, adopting the presumption of innocence may incentivize the law enforcer to exert high effort, thus increasing deterrence

\footnotetext{
${ }^{14}$ Type 2 errors refer here to the lack of detection.

${ }^{15}$ Indeed, under the presumption of innocence, the probability that an innocent citizen suffers from a type 1 error is $0<p_{i}(1-q)$, and the probability that a guilty citizen suffers from a type 2 error is $\left(1-p_{g}\right)+p_{g}(1-q)>1-p_{g}$.
} 
ceteris paribus. But let us first consider the impact of the law enforcer's effort on the crime rate.

\subsubsection{Impact of the law enforcer's effort on the crime rate}

Under the presumption of guilt, an increase in the law enforcer's effort $(q)$ decreases the probability of a type 1 error (wrongful conviction), increasing deterrence as a result. To see this, let us denote:

$$
\hat{b}_{1, l}:=\left(p_{g}-p_{i}\left(1-q_{l}\right)\right) s \text { and } \hat{b}_{1, h}:=\left(p_{g}-p_{i}\left(1-q_{h}\right)\right) s
$$

with $\hat{b}_{1, l}\left(\hat{b}_{1, h}\right)$ the deterrence threshold under the presumption of guilt and a low (high) law enforcer's effort. We have:

$$
\hat{b}_{1, h}-\hat{b}_{1, l}=p_{i} \Delta q s:=\Delta \hat{b}_{1}
$$

which confirms that the deterrence threshold increases with the law enforcer's effort since $\Delta \hat{b}_{1}>0$. This rise in deterrence may be socially desirable to the extent that society benefits from an increase in deterrence and the law enforcer's cost of effort $(k)$ is not too high. However, we know that whatever the value of $k$, the law enforcer's effort remains low if $V \geq 0$.

Under the presumption of innocence, an increase in the law enforcer's effort $(q)$ decreases the probability of a type 2 error (false acquittal), increasing deterrence as a result. To see this, let us denote:

$$
\hat{b}_{2, l}:=p_{g} q_{l} s \text { and } \hat{b}_{2, h}:=p_{g} q_{h} s
$$

with $\hat{b}_{2, l}\left(\hat{b}_{2, h}\right)$ the deterrence threshold under the presumption of innocence and a low (high) law enforcer's effort. We have:

$$
\hat{b}_{2, h}-\hat{b}_{2, l}=p_{g} \Delta q s:=\Delta \hat{b}_{2}
$$

which confirms that the deterrence threshold increases with the law enforcer's effort since 
$\Delta \hat{b}_{2}>0$. As is the case under the presumption of guilt, if the law enforcer's cost of effort $(k)$ is not too high, a high law enforcer's effort is beneficial to society since it increases deterrence.

To summarize, an increase in the law enforcer's effort increases deterrence by reducing the probability of a type 2 error (false acquittal) under the presumption of innocence, while it increases deterrence by reducing the probability of a type 1 error (wrongful conviction) under the presumption of guilt. Moreover, the increase in the deterrence threshold (and thus the decrease in the crime rate if $b$ is uniformly distributed) is larger under the presumption of innocence (since $\Delta \hat{b}_{2}>\Delta \hat{b}_{1}$ ).

\subsection{Equilibrium effort and probability of crime}

Until now, we have considered the law enforcer's prior belief that the defendant is guilty $(\alpha)$ as given. However, this probability should be regarded as endogenous to the model. In this subsection, we determine $\alpha$ and characterize the subgame equilibrium between the citizen and the law enforcer. To obtain an explicit characterization of $\alpha$, we assume in the following that the citizen's benefit from crime $(b)$ is uniformly distributed on the support $[0,1]$, and that $s \in(0,1] .^{16}$

The probability that the citizen is guilty conditionally on being detected is computed by using Bayes' Rule:

$$
\alpha=\operatorname{Pr}(\text { guilty } \mid \text { detected })=\frac{p_{g}(1-\hat{b})}{p_{g}(1-\hat{b})+p_{i} \hat{b}}
$$

with $\hat{b} \in\left\{\hat{b}_{1, l}, \hat{b}_{1, h}, \hat{b}_{2, l}, \hat{b}_{2, h}, \hat{b}_{2, m}\right\}$, depending on the applied presumption and the law enforcer's level of effort, and:

$$
\hat{b}_{2, m}:=p_{g}\left[\beta q_{h}+(1-\beta) q_{l}\right] s
$$

\footnotetext{
${ }^{16}$ Assuming that $s \in(0,1]$ allows us to avoid negative deterrence thresholds.
} 
with $\beta \in(0,1)$ the probability that the law enforcer exerts high effort. Note that the probability $\alpha$ is simultaneously the law enforcer's prior belief that a detected citizen is guilty, and his posterior belief if he obtains an uninformative signal (since the probability of obtaining an uninformative signal is independent of the citizen's guilt or innocence). This probability can also be interpreted as the court's belief when no conclusive evidence is found.

The following lemma summarizes our results about the law enforcer's effort and the probability with which a crime is committed.

Lemma 1. Assume $V \geq 0$.

1. Under the presumption of guilt, the law enforcer exerts low effort and the probability of a crime is $1-\hat{b}_{1, l}$.

2. Under the presumption of innocence, the law enforcer's effort and deterrence decrease with $k$. More specifically:

- If $k \leq k_{2, h}$ (respectively $k \geq k_{2, l}$ ), the law enforcer exerts high (low) effort and the probability of a crime is $1-\hat{b}_{2, h}\left(1-\hat{b}_{2, l}\right)$.

- If $k \in\left(k_{2, h}, k_{2, l}\right)$, the law enforcer exerts high effort with probability $\hat{\beta}_{2, m} \in(0,1)$ as defined by (40). The probability of a crime is $1-\left.\hat{b}_{2, m}\right|_{\beta=\hat{\beta}_{2, m}}$.

Proof. The proof is in appendix 1.

According to lemma 1, the law enforcer's effort may be high under the presumption of innocence, but is always low under the presumption of guilt (see figure 3). More specifically, under the presumption of innocence, the law enforcer's effort decreases with its cost, and thus the crime rate increases with the cost of the law enforcer's effort (see figure 4).

We can already view from figure 3 and figure 4 that when the policymaker chooses the presumption in order to deter crimes, there may exist a trade-off between (i) choosing the presumption of guilt to maximize deterrence for a given level of the law enforcer's effort, and (ii) choosing the presumption of innocence to induce a higher level of law enforcement effort (and thus deterrence). ${ }^{17}$

\footnotetext{
${ }^{17}$ Note that this trade-off exists only if $k<k_{2, l}$.
} 


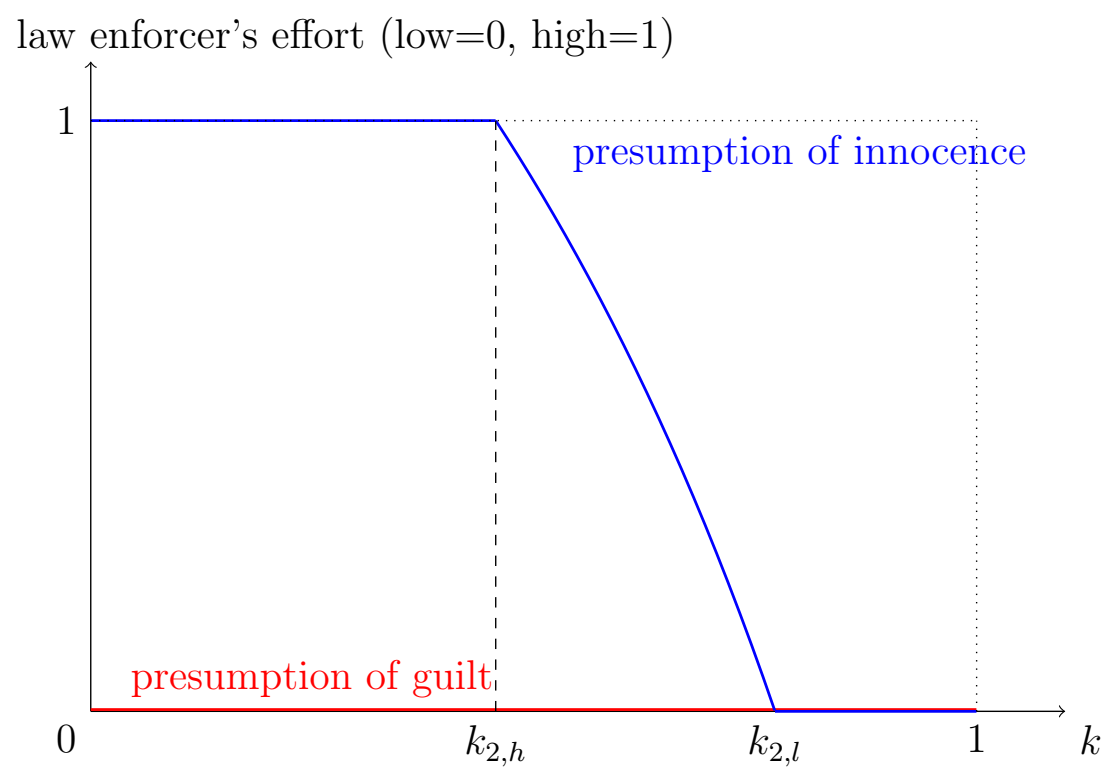

[Figure 3: Equilibrium law enforcer's effort]

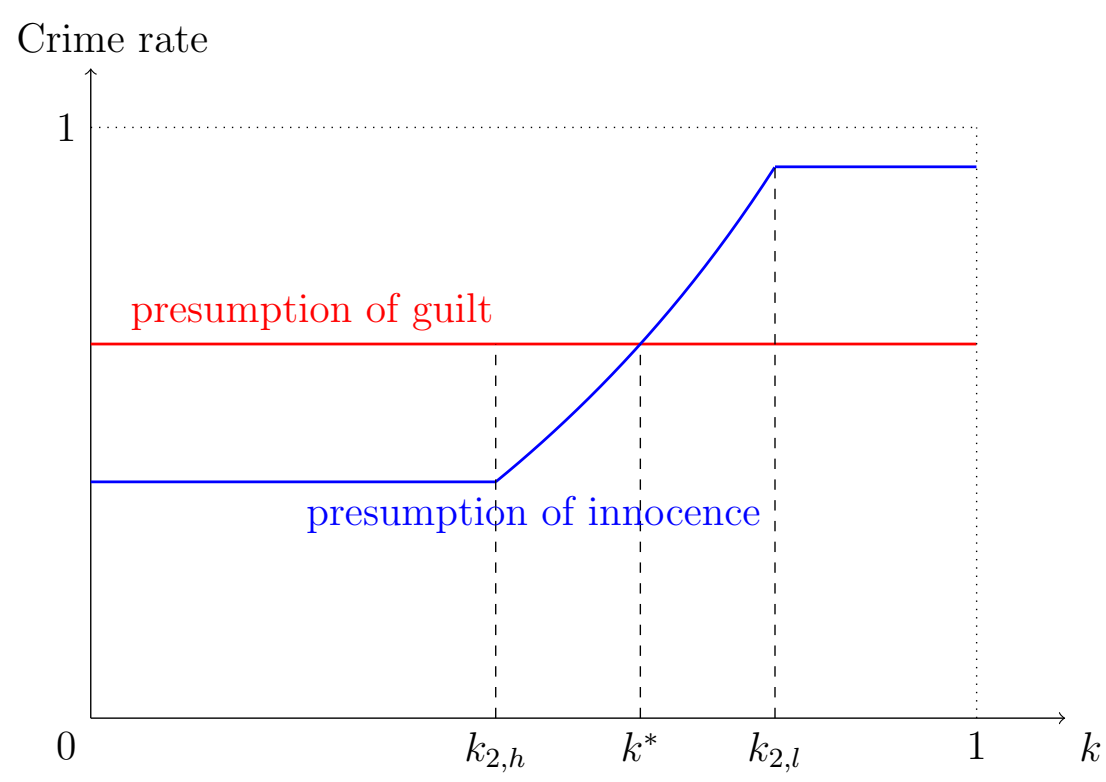

[Figure 4: Equilibrium crime rate]

The intuition of this result is fairly similar to the one highlighted by Stephenson (2011) 
when he argues that "imposing a more demanding standard of proof [...] may sometimes lead a principal to prefer a standard of proof that appears too stringent when viewed from an ex post perspective" by "worsening the agent's default payoff and thereby strengthening the agent's incentive to do research." This result will be developed further in section 4.

\section{Public policy implications}

In this section, we use the results of lemma 1 to discuss further the impact of the presumption of guilt/innocence on deterrence, and the choice of the policymaker regarding which presumption to apply and the level of the sanction.

\subsection{Deterrence}

In this subsection, we ask: What is the optimal presumption with regard to deterrence?

We have already shown that, for a given level of the law enforcer's effort, deterrence is always higher under the presumption of guilt $\left(\hat{b}_{1}>\hat{b}_{2}\right)$. The intuition behind this result is the following. When we switch from the presumption of innocence to the presumption of guilt, the probability of a type 1 error increases, while the probability of a type 2 error decreases. The magnitude of the decrease in the probability of a type 2 error is greater than the magnitude of the increase in the probability of a type 1 error. Because deterrence is equally affected by the probabilities of type 1 and type 2 errors (according to the classic result of Png, 1986), we find that the presumption of guilt maximizes deterrence.

However, considering the law enforcer's effort as given may be misleading, since this (endogeneous) effort may be higher under the presumption of innocence. Indeed, the presumption of innocence allows deterrence to be maximized if:

$$
\hat{b}_{2, m}>\hat{b}_{1, l} \Leftrightarrow \beta>\frac{\Delta p}{\Delta q} \frac{\left(1-q_{l}\right)}{p_{g}}
$$

In contrast to our result for a given effort by the law enforcer, the presumption of inno- 
cence may increase deterrence if it incentivizes the law enforcer to exert high effort, i.e. if condition (19) is satisfied.

The following proposition gives more precisely the necessary and sufficient conditions for the presumption of innocence to maximize deterrence.

Proposition 1. Assume $V \geq 0$ and:

$$
p_{g}\left(1-q_{h}\right)<p_{i}\left(1-q_{l}\right)
$$

The presumption of innocence (strictly) maximizes deterrence if:

$$
\Delta q>k\left[\frac{1}{(1+w) s}\left(1+\frac{p_{i}}{p_{g}} \frac{\hat{b}_{1, l}}{1-\hat{b}_{1, l}}\right)\right]
$$

If at least one of conditions (20) and (21) does not hold, then the presumption of guilt maximizes deterrence.

Proof. The proof is in appendix 2 .

The first condition of proposition 1 is a necessary condition ensuring that there exist some values of $\beta$ for which the presumption of innocence maximizes deterrence. The second condition of proposition 1 is a sufficient condition saying, in essence, that the presumption of innocence induces the law enforcer to choose a high effort only if the relative efficiency of his effort $(\Delta q)$ is sufficiently large when compared to its cost $(k)$. The intuition is well explained by Stephenson (2011) when applied to the standard of proof: "increasing the stringency of the standard of proof may strengthen the agent's research incentives, but only up to the point where the standard becomes so hard to satisfy that the agent is better off not trying." It will be useful to rewrite condition (21) as:

$$
k<\frac{1-\hat{b}_{1, l}}{p_{g}-\Delta p \hat{b}_{1, l}} p_{g} \Delta q(1+w) s:=k^{*}
$$

The presumption that maximizes deterrence can be characterized by a threshold rule on the cost of the law enforcer's effort: the presumption of innocence (strictly) maximizes 
deterrence only if $k<k^{*}$ and (20) is satisfied.

Example 1. The result of proposition 1 according to which the presumption of innocence may maximize deterrence can be illustrated by using the following parameter values: $p_{i}=1 / 3, p_{g}=2 / 3, q_{l}=1 / 10, q_{h}=9 / 10, w=0, s=1, k=1 / 2$ (these are the parameter values used in figure 3 and figure 4). It is easy to check that for these parameter values, the two conditions of proposition 1 are satisfied. With the presumption of guilt, the law enforcer exerts a low effort and the probability of a crime being committed by a citizen is given by $1-F\left(\hat{b}_{1, l}\right)=19 / 30 \approx 0.63$. With the presumption of innocence, the law enforcer exerts a high effort with a probability $\hat{\beta}_{2, m}=79 / 88 \approx 0.9$, and the probability of a crime being committed is $1-F\left(\hat{b}_{2, m}\right)=6 / 11 \approx 0.55$. Moreover, note that the court's belief that the citizen is guilty when evidence is uninformative and a presumption of guilt (respectively a presumption of innocence) is applied is given by $\alpha_{1} \approx 0.78$ (respectively $\alpha_{2} \approx 0.625$ ). Thus, convicting the citizen when a presumption of guilt is applied and evidence is uninformative may be consistent with a clear and convincing evidence standard, as is the case in this example. ${ }^{18}$

\subsection{Presumption of innocence or presumption of guilt?}

In this subsection, we study the choice of the presumption by the policymaker. We assume the policymaker's objective is to minimize total costs, which include the expected external harm induced by a crime, and the law enforcer's expected cost of investigative effort. Formally, total costs are:

$$
C_{i}=\left(1-F\left(\hat{b}_{i}\right)\right) h+\beta k
$$

with $i=1(i=2)$ if a presumption of guilt (innocence) principle is applied, and $h>0$ the external harm if a crime is committed.

Under conditions (20) and (21) of proposition 1, there are two effects of switching from

\footnotetext{
${ }^{18}$ According to Rizzolli and Saraceno (2013), the preponderance of evidence, clear and convincing evidence, beyond any reasonable doubt standards, "are commonly understood to roughly coincide with the $50 \%, 75 \%$ and $95 \%$ thresholds respectively."
} 
the presumption of guilt to the presumption of innocence for the policymaker. On the one hand, deterrence increases (and thus the expected external harm decreases). On the other hand, the law enforcer exerts high effort, and thus incurs a higher cost. As a consequence, there exists a trade-off between these two concerns.

The following corollary gives the conditions under which the policymaker will choose the presumption of innocence.

Corollary 1. Assume $V \geq 0$.

1. If $k \leq k_{2, h}$ (high law enforcer's effort under the presumption of innocence) and (21) is satisfied, the policymaker chooses the presumption of innocence if:

$$
h \geq \frac{k}{\hat{b}_{2, h}-\hat{b}_{1, l}}
$$

2. If $k \in\left(k_{2, h}, k_{2, l}\right)$ (high law enforcer's effort with probability $\hat{\beta}_{2, m} \in(0,1)$ under the presumption of innocence) and (21) is satisfied, the policymaker chooses the presumption of innocence if:

$$
h \geq \frac{\hat{\beta}_{2, m} k}{\left.\hat{b}_{2, m}\right|_{\beta=\hat{\beta}_{2, m}}-\hat{b}_{1, l}}
$$

3. If $k \geq k_{2, l}$ (low law enforcer's effort under the presumption of innocence), the policymaker never chooses the presumption of innocence.

Proof. The proof is in appendix 3.

The intuition for this corollary is the following. The policymaker chooses the presumption of innocence if $C_{1} \geq C_{2}$. Since deterrence is higher under the presumption of guilt when the law enforcer exerts low effort whatever the presumption $\left(\hat{b}_{1, l}>\hat{b}_{2, l}\right)$, choosing the presumption of innocence may be desirable if and only if (i) it incentivizes the law enforcer to exert high effort with a strictly positive probability (i.e. if $k<k_{2, l}$ ), and (ii) it increases deterrence (the conditions of proposition 1 are satisfied). Even under these conditions, the presumption of innocence is not always optimal due to the cost of the law enforcer's effort that the policymaker internalizes, which has to be compared to the benefit of an increase in deterrence. Since this benefit increases with the external 
harm of a crime, the presumption of innocence tends to be more desirable if this external harm $(h)$ is substantial relatively to the expected cost of the law enforcer's effort $(\beta k)$. This result is consistent with the observation that the presumption of innocence is generally observed in criminal law, and the pro-defendant bias is emphasized more than in civil or administrative law for instance, although there exist other explanations for this pro-defendant bias in criminal law (see among others Rizzolli, 2016; Rizzolli and Saraceno, 2013; Nicita and Rizzolli (2014); Mungan, 2011; Obidzinski and Oytana, 2017).

Notice that the total cost function considered here can be discussed on a number of points. First, we have not included in this function the benefit derived from committing a crime by the offender. Including this benefit is quite controversial in the law and economics literature. However, our normative results remain valid as long as society wishes to increase deterrence and makes a trade-off between this objective and the cost of achieving it. Second, we have implicitly assumed that the punishment is costless. This assumption is valid only if the punishment is limited to a monetary fine, but no longer holds if the sanction is for example imprisonment. Assume that punishment is costly. The costs of punishment are higher under the presumption of guilt if the probability of a conviction is higher under this standard, that is if:

$$
\left(1-\hat{b}_{1}\right) p_{g}+\hat{b}_{1} p_{i}\left(1-q_{1}\right)>\left(1-\hat{b}_{2}\right) p_{g} q_{2}
$$

with $q_{1}\left(q_{2}\right)$ the probability that the law enforcer will obtain informative evidence from his effort at equilibrium under the presumption of guilt (innocence). For parameter values such that the policymaker prefers the presumption of innocence over the presumption of guilt, we have $\hat{b}_{1}<\hat{b}_{2}$ (the policymaker is willing to accept a lower level of deterrence under the presumption of guilt to avoid the positive expected cost of the law enforcer's effort when he chooses the presumption of innocence). As a consequence, condition (26) is always satisfied: the expected cost of punishment to society is higher under the presumption of guilt. In other words, a presumption of innocence is more often optimal when we introduce costly punishments in our model. This result is consistent with the findings of Rizzolli and Saraceno (2013). 


\subsection{The optimal sanction}

Even if our main focus is on the choice of the principle of presumption, some interesting results and intuitions regarding the optimal level of the sanction initially chosen by the policymaker can be derived from our model. We still assume in this subsection that $V \geq 0$ and the benefit of the crime is uniformly distributed.

Under the presumption of guilt, we have shown that the law enforcer's effort is always low. This result holds whatever the value of the sanction $s>0$. Moreover, it is easy to show that the deterrence threshold increases with $s$ (i.e. $\partial \hat{b}_{1, l} / \partial s>0$ ). Assuming that the sanction $s$ is a monetary fine, the policymaker should choose the maximum possible fine. This result is consistent with the standard Beckerian framework.

Under the presumption of innocence, the results are more complex. First, for a given level of the law enforcer's effort, deterrence increases with respect to the level of $s\left(\partial \hat{b}_{2} / \partial s>0\right)$. Second, for a given crime rate (and thus a given $\alpha$ ), the law enforcer's effort increases with respect to $s$. This result is intuitive since the law enforcer's objective is to maximize the (weighted) expected punishment when $V \geq 0$. However, at the equilibrium, we need to consider simultaneously the citizen's decision to commit a crime and the law enforcer's choice of effort. In this case, there are indirect effects due to the interaction between deterrence and the law enforcer's incentive to exert a high effort. Indeed, recall that the law enforcer strictly prefers to exert high effort if:

$$
\Delta u_{2}^{p}=\alpha \Delta q(1+w) s-k \geq 0
$$

An increase in $s$ has two opposite effects on $\Delta u_{2}^{p}$ (i.e. on the law enforcer's surplus if he exerts high effort):

$$
\frac{\partial \Delta u_{2}^{p}}{\partial s}=\underbrace{\alpha \Delta q(1+w)}_{\text {direct effect }(>0)}+\underbrace{\frac{\partial \alpha}{\partial s} \Delta q(1+w)}_{\text {indirect effect }(<0)} s
$$

The first term is positive and is the direct effect of increasing the level of the sanction $(s)$ : a higher level of $s$ increases the law enforcer's payoff in the event he obtains a conviction, incentivizing him to increase his effort. The second term is negative and is the indirect 
effect of increasing $s$ on the law enforcer's incentive to exert a high effort via his belief as to the citizen's type $(\alpha)$ : deterrence increases with $s$, decreasing the crime rate and thus the law enforcer's belief that a detected citizen is guilty $(\alpha)$. As a result, his incentive to choose a high level of effort is weakened, since the increase in the probability with which a high effort allows the law enforcer to secure a conviction is reduced. If the indirect effect dominates the direct effect, then the probability with which the law enforcer chooses to exert a high effort is nonincreasing with respect to the level of the sanction. This result is illustrated in the context of the mixed strategy equilibrium in example $2 .{ }^{19}$

Example 2. Consider the following parameter values: $p_{i}=1 / 2, p_{g}=0.9, q_{l}=0.2$, $q_{h}=0.8, w=0.3, k=0.36$. Under the presumption of innocence, and assuming $s=0.8$, the law enforcer exerts a high effort with a probability $\hat{\beta}_{2, m} \approx 0.984$. Increasing the level of the sanction to $s=1$ lowers the probability with which the law enforcer exerts a high effort to $\hat{\beta}_{2, m} \approx 0.921$.

A similar reasoning applies to deterrence since, assuming the mixed strategy equilibrium prevails, we have:

$$
\frac{\partial \hat{b}_{2, m}}{\partial s}=\underbrace{p_{g}\left[\beta q_{h}+(1-\beta) q_{l}\right]}_{\text {direct effect }(>0)}+\underbrace{p_{g} \frac{\partial \beta}{\partial s} \Delta q s}_{\text {indirect effect }}>0
$$

The first term is positive and is the direct effect of an increase in $s$ on deterrence. The second term is the effect of an increase in $s$ on the law enforcer's choice of effort, which (indirectly) impacts deterrence. The sign of this indirect effect is ambiguous since, as illustrated above, the probability with which the law enforcer exerts high effort may increase or decrease with $s$ (i.e. $\partial \beta / \partial s$ may be positive or negative). However, even if the indirect effect is negative, the overall effect of an increase in the sanction on deterrence is always positive. The intuition is the following. As explained above, an increase in $s$ may reduce the probability of the law enforcer's effort being high $(\partial \beta / \partial s<0)$ and

\footnotetext{
${ }^{19}$ Numerical simulations show that the probability with which the law enforcer exerts a high effort tends to decrease with respect to the level of the sanction for high values of $s$ and for low to intermediate values of $k$.
} 
thus indirectly deterrence, but only because deterrence increases as a consequence of the higher sanction (i.e. the direct effect highlighted in (29) is sufficiently strong to have $\left.\partial \hat{b}_{2, m} / \partial s>0\right)$. Thus, at equilibrium, we cannot simultaneously have a decrease in the law enforcer's effort and in deterrence. This implies that, even in the event that the probability with which the law enforcer exerts a high effort decreases with respect to $s$, this effect cannot be sufficiently strong to induce a decrease in deterrence. In other words, we always have $\partial \hat{b}_{2} / \partial s>0$ at equilibrium. Again, this result is consistent with the standard Beckerian framework.

A last question that can be addressed regarding the level of the sanction is: How does an increase in $s$ impact the desirability of choosing the presumption of innocence (assuming for simplicity that the policymaker's objective is to increase deterrence)? The following corollary gives the condition under which the set of values of $k$ for which the presumption of innocence maximizes deterrence expands with $s$.

Corollary 2. Assume condition (20) holds. The set of values of $k$ for which the presumption of innocence maximizes deterrence expands with $s$ if:

$$
p_{g}\left(1-2 \hat{b}_{1, l}\right)+\Delta p\left(\hat{b}_{1, l}\right)^{2}>0
$$

Proof. The proof is in appendix 4.

Corollary 2 shows that an increase in the magnitude of the sanction increases the range of values of $k$ for which presumption of innocence maximizes deterrence if (30) is satisfied. This condition tends to be more easily satisfied if $\hat{b}_{1, l}$ is low, and thus if the level of the sanction $(s)$ is low. In other words, for some parameter values, we are able to find a threshold for the level of the sanction such that presumption of innocence is more often beneficial (in the sense that it increases deterrence) if the present level of the sanction lies below this threshold, and conversely. 


\section{A law enforcer averse to type 1 errors}

Until now, we have assumed that $V \geq 0$. Alternatively, in this section, we assume that $V<0$ : the law enforcer suffers a loss when an innocent person is convicted. ${ }^{20}$

Consider first the principle of the presumption of innocence. The payoffs of the law enforcer are still given by (4) if he chooses low effort, and by (5) if he chooses high effort. These payoffs do not depend on $V$ : as before, the law enforcer (strictly) prefers to exert high effort if and only if $k<k_{2}$. Moreover, the deterrence threshold is still $\hat{b}_{2}$. As a consequence, the results and the intuitions behind part 2 of lemma 1 remain valid.

Now consider the presumption of guilt principle. This case is more complex. The payoff of the law enforcer is still given by (1) if he chooses low effort, and by (2) if he chooses high effort. However, these payoffs depend on $V$. More specifically, recall that the law enforcer (strictly) prefers to exert high effort if and only if $k<k_{1}$, with $k_{1}=-(1-\alpha) \Delta q V s$. Since $V<0$, the threshold $k_{1}$ is now positive $\left(k_{1}>0\right)$. More specifically, assuming that the law enforcer's prior belief $\alpha$ is given, the law enforcer exerts high effort if his cost of effort $(k)$ is not too large when compared to his prior that the citizen is innocent $(1-\alpha)$, the relative efficiency of his effort $(\Delta q)$, the sanction $(s)$, and if the disutility of convicting an innocent person is important ( $V$ is low). Thus, the law enforcer may now choose to exert high effort under the presumption of guilt, which was not the case previously when $V \geq 0$. If the law enforcer chooses to exert low (high) effort, the deterrence threshold is $\hat{b}_{1, l}\left(\hat{b}_{1, h}\right)$, as specified in $(13)$.

To summarize, when the law enforcer is averse to type 1 error, the effort decision is not affected under the presumption of innocence. Indeed, in the extreme case depicted in the model, the risk of a type 1 error (convicting an innocent person) does not exist under the presumption of innocence. On the contrary, if a presumption of guilt is applied, the effort decision may be affected by the fact that the law enforcer is averse to type 1 errors and tries to avoid them: it is now possible that the law enforcer will exert a high effort under

\footnotetext{
${ }^{20}$ For example, if $V=-1$ and $w=0$, the law enforcer gains by convicting guilty citizens as much as he loses by acquitting innocent citizens (pro-justice law enforcer).
} 
the presumption of guilt. Therefore, the need to switch to the presumption of innocence is likely to be weaker.

Let us develop further the case of the presumption of guilt. Just as with the presumption of innocence, the citizen's decision whether or not to commit a crime depends on the law enforcer's effort, and vice-versa. However, and conversely to what happens with a high standard, the citizen and law enforcer strategies are self-reinforcing under the presumption of guilt: the law enforcer's best response may be to choose a high effort when the citizen believes he will do so, and conversely. This suggests that there does not exist a mixed strategy equilibrium, but that there may be two pure strategy equilibria that overlap for some parameter values: one with low law enforcer's effort and deterrence, and the other with high law enforcer's effort and deterrence.

We are interested in determining whether our main result, according to which the presumption of innocence may provide more deterrence when compared to the presumption of guilt, is still valid when $V<0$. To this end, assume that the law enforcer always exerts high effort under the presumption of guilt when $k \leq k_{1, h}$ (this is the equilibrium selection the most unfavorable to maintain our result). We can state the following proposition.

Proposition 2. Assume $V<0$. There exist positive values of $k$ for which the presumption of innocence (strictly) maximizes deterrence if (20) holds and:

$$
\frac{1+w}{|V|}>\frac{\hat{b}_{1, h}}{1-\hat{b}_{1, l}} \frac{p_{i}\left(p_{g}-\Delta p \hat{b}_{1, l}\right)}{p_{g}\left(p_{g}-\Delta p \hat{b}_{1, h}\right)}
$$

If (20) and (31) are satisfied, deterrence is (strictly) maximized under the presumption of innocence if $k \in\left(k_{1, h}, k^{*}\right)$.

Proof. The proof is in appendix 5 .

In essence, proposition 2 says that our main result, according to which the presumption of innocence may be optimal when the policymaker's main objective is to increase deterrence (because it incentivizes the law enforcer to choose a high level of effort for a larger range 
of the parameter values, and this effort significantly increases the accuracy of the court's decision-making and thus deterrence), remains valid as long as the law enforcer's aversion towards type 1 errors is not too high when compared to his aversion towards type 2 errors (i.e. when $(1+w) /|V|$ is large enough).

\section{Conclusion}

This paper presents a model of evidence gathering by an investigating agent (for instance a prosecutor or a police officer), and studies how the choice of criminal procedure rules (focusing on the presumption of innocence vs culpability) by a policymaker may influence the law enforcer's choice regarding his level of effort. The general idea is that the objectives of the law enforcer are not aligned with those of society, represented by the benevolent policymaker whose objective is to minimize total costs (total costs are the sum of external harm induced by crimes and investigating effort costs). As such, the presumption of innocence can be used as an incentive device to increase investigating effort (at a cost). Indeed, under this principle of presumption, the probability the law enforcer will secure a conviction increases with his effort. Surely the presumption of innocence shall not be justified only as an incentive device, since there are many considerations of fairness or humanitarian or philosophical justifications for the presumption of innocence. However, what we show is that the pro-defendant bias in criminal procedure (figured here by the presumption of innocence) might not interfere with deterrence.

We find that for a given level of the law enforcer's effort, deterrence is higher under the presumption of guilt. However, assuming that the law enforcer maximizes the probability of a conviction (weighted by the magnitude of the sanction) minus his cost of effort, we show that, under some specified conditions, his effort may increase under the presumption of innocence. As a consequence, the policymaker may choose the presumption of innocence in order to increase deterrence. This is our main result. In an extension, we show that this result holds even if the law enforcer is averse to wrongful convictions (under more restrictive conditions however). Moreover, we find that the optimal sanction is maximal (despite the fact that increasing the sanction may reduce the law enforcer's 
effort), and that the presumption of innocence may be more or less desirable when the sanction increases.

Our main result is in line with the arguments of Friedman (1999) and the public choice perspective of Hylton and Khanna (2007). The idea is that the pro-defendant bias of criminal procedure can be explained by the tendency of criminal law enforcers to punish excessively (in order to extract rents). In our paper, the investigating agent's interests are not perfectly aligned with those of society, as he is mainly interested in the sentence weighted probability of conviction, rather than in deterrence. Imposing ex ante innocence as the null hypothesis reduces the probability of shirking as well as the probability of occurrence of a type 1 error. In a sense, the presumption of innocence limits the ability of "law enforcers to use the criminal process to obtain [their] own ends." ${ }^{21}$ This result is also consistent (in a largely different setting) with the findings of Dharmapala et al. (2016) where the judiciary controls ex post police work. In our model, the judiciary reviews the work of the investigating agent through the rules of procedure.

Some of our assumptions ought to be discussed. First, we have assumed that the law enforcer does not have the opportunity to manipulate or hide evidence, and that disclosure of evidence is mandatory. This assumption is clearly a simplification. Indeed, if the law enforcer had the ability to perfectly well hide the evidence he has gathered, and assuming his expected payoff increases with the probability that he obtains a conviction (as this is the case in our main model), he would never reveal evidence of innocence. However, we believe our results remain true (albeit weakened) if there is a positive probability that some exculpatory evidence may leak (as in Garoupa and Rizzolli, 2011). Second, we have assumed (following Stephenson, 2008) that the court cannot verify the information provided by the law enforcer. This enabled us to model in an easy way the idea that the law enforcer has better evidence-gathering skills than the court. However, it can be imagined that the court is able to hire court-appointed experts, or may use the information produced by the parties to assess the quality of the information provided by the law enforcer. Such an extension of our model would be interesting if it is assumed that

\footnotetext{
${ }^{21}$ This expression is borrowed from Hylton and Khanna (2007)
} 
the law enforcer has the possibility to manipulate or hide some of the evidence he has obtained.

\section{Appendix}

\section{Appendix 1: proof of lemma 1}

We characterize the citizen and law enforcer's best responses as a function of the principle of presumption. Under the presumption of guilt, the law enforcer's effort is always low. We then have:

$$
\alpha=\frac{p_{g}\left(1-\hat{b}_{1, l}\right)}{p_{g}\left(1-\hat{b}_{1, l}\right)+p_{i} \hat{b}_{1, l}}:=\alpha_{1, l}
$$

Under the presumption of guilt, the subgame equilibrium is characterized by a deterrence threshold $\hat{b}_{1, l}$, a probability $\alpha_{1, l}$ that the law enforcer faces a guilty citizen if an individual is detected, and a low law enforcer's effort $\left(q=q_{l}\right)$.

The case of the presumption of innocence is more complex, since the law enforcer's effort may be either low or high. Indeed, the citizen's decision whether or not to commit a crime depends on the law enforcer's effort, and conversely. As a consequence, three kinds of equilibria exist depending on the parameter values: two in pure strategy and one in mixed strategy.

In one of the pure strategy equilibria, the law enforcer's effort is low $\left(q=q_{l}\right)$. Thus, the

deterrence threshold is given by $\hat{b}_{2, l}$, and the probability that the law enforcer faces a guilty citizen if an individual is detected is:

$$
\alpha=\frac{p_{g}\left(1-\hat{b}_{2, l}\right)}{p_{g}\left(1-\hat{b}_{2, l}\right)+p_{i} \hat{b}_{2, l}}:=\alpha_{2, l}
$$

This equilibrium arises if the law enforcer does not want to deviate unilaterally to exert 
a high effort. The corresponding condition is:

$$
u_{2, l}^{p}\left(\alpha=\alpha_{2, l}\right) \geq u_{2, h}^{p}\left(\alpha=\alpha_{2, l}\right) \Leftrightarrow k \geq \frac{\Delta q\left(1-\hat{b}_{2, l}\right)}{1-\Delta p q_{l} s}(1+w) s:=k_{2, l}
$$

with $\Delta p=p_{g}-p_{i}$.

In the other pure strategy equilibrium, the law enforcer's effort is high $\left(q=q_{h}\right)$. Thus, the deterrence threshold is given by $\hat{b}_{2, h}$, and the probability that the law enforcer faces a guilty citizen if an individual is detected is:

$$
\alpha=\frac{p_{g}\left(1-\hat{b}_{2, h}\right)}{p_{g}\left(1-\hat{b}_{2, h}\right)+p_{i} \hat{b}_{2, h}}:=\alpha_{2, h}
$$

This equilibrium arises if the law enforcer does not want to deviate unilaterally to exert a low effort. The corresponding condition is:

$$
u_{2, h}^{p}\left(\alpha=\alpha_{2, h}\right) \geq u_{2, l}^{p}\left(\alpha=\alpha_{2, h}\right) \Leftrightarrow k \leq \frac{\Delta q\left(1-\hat{b}_{2, h}\right)}{1-\Delta p q_{h} s}(1+w) s:=k_{2, h}
$$

Note that $k_{2, h}<k_{2, l}$, which suggests that there exists a mixed strategy equilibrium for $k \in\left(k_{2, h}, k_{2, l}\right)$.

The intuition for the existence of the mixed strategy equilibrium is the following. The law enforcer's incentive to exert high effort increases with respect to $\alpha$. Indeed, a higher $\alpha$ implies a higher marginal increase in the probability of a conviction with the law enforcer's effort. However, as the law enforcer's effort increases, the deterrence threshold increases too (fewer citizens want to commit crimes), thus decreasing $\alpha$. Accordingly, the law enforcer's best response may be to choose high effort when the citizen believes he will choose low effort, and conversely. As a consequence, there exists a mixed strategy equilibrium in which the law enforcer chooses high effort with a probability $\beta \in(0,1)$. The deterrence threshold may be rewritten as:

$$
\hat{b}_{2, m}:=p_{g}\left[\beta q_{h}+(1-\beta) q_{l}\right] s
$$


The probability that the law enforcer faces a guilty citizen is:

$$
\alpha=\frac{p_{g}\left(1-\hat{b}_{2, m}\right)}{p_{g}\left(1-\hat{b}_{2, m}\right)+p_{i} \hat{b}_{2, m}}:=\alpha_{2, m}
$$

In the mixed strategy equilibrium, the probability $\beta$ should be such that the law enforcer is indifferent between a low and a high effort. Formally, the following condition must hold:

$$
k=\alpha_{2, m} \Delta q(1+w) s
$$

Substituting $\alpha_{2, m}$ and $\hat{b}_{2, m}$ according to (37) and (38), and solving for $\beta$, yields the following expression:

$$
\beta=\frac{k\left(1-\Delta p q_{l} s\right)-\Delta q\left(1-\hat{b}_{2, l}\right)(1+w) s}{\Delta q\left(k \Delta p-\Delta \hat{b}_{2}(1+w)\right) s}:=\hat{\beta}_{2, m}
$$

The law enforcer chooses to exert high (low) effort with a probability included in $(0,1)$ if the parameter values are such that $\hat{\beta}_{2, m} \in(0,1)$.

\section{Appendix 2: proof of proposition 1}

A necessary condition for the presumption of innocence to maximize deterrence is that $\hat{b}_{2, h}>\hat{b}_{1, l}$. This condition simplifies to (20). If condition (20) is satisfied, there exist values of $\beta$ such that the presumption of innocence maximizes deterrence if condition (19) is satisfied. Substituting $\beta$ for $\hat{\beta}_{2, m}$ in (19) and rearranging yields condition (21).

\section{Appendix 3: proof of corollary 1}

If there is a presumption of guilt, the law enforcer's effort is low for $V \geq 0$ and total expected costs are:

$$
C_{1}=\left(1-\hat{b}_{1, l}\right) h
$$

Assume that $k \leq k_{2, h}$. The law enforcer's effort is high under the presumption of innocence and, as a result, deterrence increases when switching from the presumption of guilt 
to the presumption of innocence if (21) is satisfied. Total costs are:

$$
C_{2, h}=\left(1-\hat{b}_{2, h}\right) h+k
$$

The policymaker chooses the presumption of innocence if:

$$
C_{1} \geq C_{2, h} \Leftrightarrow\left(1-\hat{b}_{1, l}\right) h \geq\left(1-\hat{b}_{2, h}\right) h+k
$$

After rearranging, this equation is equivalent to (24).

Assume now that $k \in\left(k_{2, h}, k_{2, l}\right)$. Deterrence increases when switching from the presumption of guilt to the presumption of innocence if (21) is satisfied. Total costs are:

$$
C_{2, m}=\left(1-\left.\hat{b}_{2, m}\right|_{\beta=\hat{\beta}_{2, m}}\right) h+\hat{\beta}_{2, m} k
$$

The policymaker chooses the presumption of innocence if:

$$
C_{1} \geq C_{2, m} \Leftrightarrow\left(1-\hat{b}_{1, l}\right) h \geq\left(1-\left.\hat{b}_{2, m}\right|_{\beta=\hat{\beta}_{2, m}}\right) h+\hat{\beta}_{2, m} k
$$

After rearranging, this equation is equivalent to (25).

Finally, assume that $k \geq k_{2, h}$. Condition (19) is never satisfied for $\beta=0$ : deterrence does not increase when switching from the presumption of guilt to the presumption of innocence, and thus the policymaker always chooses the presumption of guilt.

\section{Appendix 4: proof of corollary 2}

Under condition (20), we have $\hat{b}_{2, l}<\hat{b}_{1, l}<\hat{b}_{2, h}$ and $\partial \hat{b}_{2, m} / \partial k<0$. Thus, there exists a unique threshold of $k$ such that deterrence is maximized. From (21), this threshold is given by (22). The set of values of $k$ for which the presumption of innocence maximizes deterrence expands with $s$ if and only if $\partial k_{2}^{*} / \partial s>0$. This condition simplifies to (30). 


\section{Appendix 5: proof of proposition 2}

In the first pure strategy equilibrium, the law enforcer's effort is low $\left(q=q_{l}\right)$. Thus, the deterrence threshold is given by $\hat{b}_{1, l}$, and $\alpha=\alpha_{1, l}$ as defined in (32). This equilibrium arises if the law enforcer does not want to deviate to exert a high effort. The corresponding condition is:

$$
k \geq-\left(1-\alpha_{1, l}\right) \Delta q V s \Leftrightarrow k \geq-\frac{p_{i} \hat{b}_{1, l}}{p_{g}-\Delta p \hat{b}_{1, l}} \Delta q V s:=k_{1, l}
$$

In the second pure strategy equilibrium, the law enforcer's effort is high $\left(q=q_{h}\right)$. Thus, the deterrence threshold is given by $\hat{b}_{1, h}$, and:

$$
\alpha=\frac{p_{g}\left(1-\hat{b}_{1, h}\right)}{p_{g}\left(1-\hat{b}_{1, h}\right)+p_{i} \hat{b}_{1, h}}:=\alpha_{1, h}
$$

This equilibrium arises if the law enforcer does not want to deviate to exert a low effort. The corresponding condition is:

$$
k \leq-\left(1-\alpha_{1, h}\right) \Delta q V s \Leftrightarrow k \leq-\frac{p_{i} \hat{b}_{1, h}}{p_{g}-\Delta p \hat{b}_{1, h}} \Delta q V s:=k_{1, h}
$$

Note that $k_{1, l}<k_{1, h}$, which suggests that the two pure strategy equilibria overlap for $k \in\left[k_{1, l}, k_{1, h}\right]$.

Condition (20) is a necessary condition ensuring that there exist strictly positive values of $k$ such that deterrence is maximized under the presumption of innocence, given a low effort of the law enforcer under the presumption of guilt. If it holds, deterrence may be maximized by the presumption of innocence only if the law enforcer's effort is low under the presumption of guilt (since $\hat{b}_{1, h}>\hat{b}_{2, h}$ ), that is if $k>k_{1, h}$ (recall that we assume the equilibrium in which the law enforcer's effort is high prevails over the equilibrium in which the law enforcer's effort is low). Moreover, and as shown in proposition 1, the presumption of innocence maximizes deterrence if $k<k^{*}$ when the law enforcer's effort is low under the presumption of guilt. Thus, the presumption of innocence maximizes deterrence only if $k_{1, h}<k<k^{*}$. The set of values of $k$ satisfying this condition is nonempty if $k_{1, h}<k^{*}$, which (after rearranging) is equivalent to 
condition (31). 


\section{References}

Bar-Gill, O. and Ayal, O. G. (2006). Plea bargains only for the guilty. The Journal of Law ES Economics, 49(1):353-364.

Becker, G. S. (1968). Crime and punishment: An economic approach. Journal of Political Economy, 76(2):169-217.

Becker, G. S. and Stigler, G. J. (1974). Law enforcement, malfeasance, and compensation of enforcers. The Journal of Legal Studies, 3(1):1-18.

Bowles, R. and Garoupa, N. (1997). Casual police corruption and the economics of crime. International Review of Law and Economics, 17(1):75-87.

Boylan, R. T. (2005). What do prosecutors maximize? Evidence from the careers of U.S. attorneys. American Law and Economics Review, 7(2):379-402.

Deffains, B. and Demougin, D. (2008). The inquisitorial and the adversarial procedure in a criminal court setting. Journal of Institutional and Theoretical Economics, 164(1):3143.

Dharmapala, D., Garoupa, N., and McAdams, R. H. (2016). Punitive police? Agency costs, law enforcement, and criminal procedure. Journal of Legal Studies, 45(1).

Easterbrook, F. H. (1983). Criminal procedure as a market system. Journal of Legal Studies, 12(2):289-332.

Emons, W. and Fluet, C. (2009). Accuracy versus falsification costs: The optimal amount of evidence under different procedures. The Journal of Law, Economics, \& Organization, 25(1):134-156.

Friedman, D. (1999). Why not hang them all: The virtues of inefficient punishment. Journal of Political Economy, 107(6):S259-S269.

Friedman, R. D. (1992). Toward a partial economic, game-theoretic analysis of hearsay. Minnesota Law Review, 76:723-796. 
Garoupa, N. (2009). Some reflections on the economics of prosecutors: Mandatory vs. selective prosecution. International Review of Law and Economics, 29(1):25-28.

Garoupa, N. (2018). Explaining the standard of proof in criminal law: A new insight. Supreme Court Economic Review, 26.

Garoupa, N. and Klerman, D. (2002). Optimal law enforcement with a rent-seeking government. American Law and Economics Review, 4(1):116-140.

Garoupa, N. and Rizzolli, M. (2011). The Brady rule may hurt the innocent. American Law and Economics Review, 13(1):168-200.

Glaeser, E. L., Kessler, D. P., and Piehl, A. M. (2000). What do prosecutors maximize? An analysis of the federalization of drug crimes. American Law and Economics Review, 2(2):259-290.

Gordon, S. C. and Huber, G. A. (2002). Citizen oversight and the electoral incentives of criminal prosecutors. American Journal of Political Science, 46(2):334-351.

Gordon, S. C. and Huber, G. A. (2009). The political economy of prosecution. Annual Review of Law and Social Science, 5:135-156.

Hay, B. and Spier, K. E. (1997). Burdens of proof in civil litigation: An economic perspective. Journal of Legal Studies, 26(26):413-431.

Hylton, K. N. and Khanna, V. (2007). A public choice theory of criminal procedure. Supreme Court Economic Review, 15(1):61-118.

Kahn, N. E., Gupta-Kagan, J., and Hansen, M. E. (2017). The standard of proof in the substantiation of child abuse and neglect. Journal of Empirical Legal Studies, $14(2): 333-369$.

Kaplow, L. (1994). The value of accuracy in adjudication: An economic analysis. The Journal of Legal Studies, 23(1):307-401.

Kaplow, L. (2011a). On the optimal burden of proof. Journal of Political Economy, 119(6):1104-1140. 
Kaplow, L. (2011b). Optimal proof burdens, deterrence, and the chilling of desirable behavior. American Economic Review, 101(3):277-80.

Kaplow, L. and Shavell, S. (1994). Accuracy in the determination of liability. Journal of Law and Economics, 37(1):1-15.

Kitai-Sangero, R. (2009). The limits of preventive detention. McGeorge Law Review, 40(4):903-934.

Landes, W. M. (1971). An economic analysis of the courts. Journal of Law and Economics, 14(1):61-107.

Lando, H. (2009). Prevention of crime and the optimal standard of proof in criminal law. Review of Law \&3 Economics, 114(1):33-52.

Langlais, E. and Obidzinski, M. (2017). Law enforcement with a democratic government. American Law and Economics Review, 19(1):162-201.

Lemos, M. H. and Minzner, M. (2014). For-profit public enforcement. Harvard Law Review, 127(3):853-913.

Levine, M. (1998). Do standards of proof affect decision making in child protection investigations? Law and Human Behavior, 22(3):341-347.

McCannon, B. C. (2013). Prosecutor elections, mistakes, and appeals. Journal of Empirical Legal Studies, 10(4):696-714.

Miceli, T. (1990). Optimal prosecution of defendants whose guilt is uncertain. Journal of Law, Economics, and Organization, 6(1):189-201.

Miceli, T. (1991). Optimal criminal procedure: Fairness and deterrence. International Review of Law and Economics, 11(1):3-10.

Mungan, M. C. (2011). A utilitarian justification for heightened standards of proof in criminal trials. Journal of Institutional and Theoretical Economics, 167(2):352-370.

Nicita, A. and Rizzolli, M. (2014). In dubio pro reo. Behavioral explanations of prodefendant bias in procedures. CESifo Economic Studies, 60(3):554-580. 
Obidzinski, M. and Oytana, Y. (2017). How does the probability of wrongful conviction affect the standard of proof? Working paper.

Png, I. P. L. (1986). Optimal subsidies and damages in the presence of judicial error. International Review of Law and Economics, 6(1):101-105.

Reinganum, J. F. (1988). Plea bargaining and prosecutorial discretion. The American Economic Review, 78(4):713-728.

Rizzolli, M. (2016). Adjudication type i and type ii errors. Forthcoming in the Encyclopedia of Law and Economics.

Rizzolli, M. and Saraceno, M. (2013). Better that ten guilty persons escape: punishment costs explain the standard of evidence. Public Choice, 155(3):395-411.

Rubinfeld, D. L. and Sappington, D. E. M. (1987). Efficient awards and standards of proof in judicial proceedings. The RAND Journal of Economics, 18(2):308-315.

Shin, H. S. (1994). The burden of proof in a game of persuasion. Journal of Economic Theory, 64(1):253-264.

Shotts, K. W. and Wiseman, A. E. (2010). The politics of investigations and regulatory enforcement by independent agents and cabinet appointees. The Journal of Politics, 92(1):209-226.

Stephenson, M. C. (2008). Evidentiary standards and information acquisition in public law. American Law and Economics Review, 10(2):351-387.

Stephenson, M. C. (2011). Information acquisition and institutional design. Harvard Law Review, 124(6):1422-1483.

Tadros, V. (2007). Rethinking the presumption of innocence. Criminal Law and Philosophy, 1(2):193-213.

Wickelgren, A. L. (2003). Justifying imprisonment: On the optimality of excessively costly punishment. American Law and Economics Review, 5(2):377-411. 
18-6. Ethnic Discrimination in Rental Housing Market: An Experiment in New Caledonia

Mathieu Bunel, Samuel Gorohouna, Yannick L'Horty, Pascale Petit, Catherine Ris

18-5. Evaluating the impact of firm tax credits. Results from the French natural experiment CICE

Fabrice Gilles, Yannick L'Horty, Ferhat Mihoubi, Xi Yang

18-4. Impact of type 2 diabetes on health expenditure: an estimation based on individual administrative data

François-Olivier Baudot, Anne-Sophie Aguadé,Thomas Barnay, Christelle GastaldiMénager, Anne Fargot-Campagna

18-3. How does labour market history influence the access to hiring interviews? Emmanuel Duguet, Rémi Le Gall, Yannick L'Horty, Pascale Petit

18-2. Occupational mobility and vocational training over the life cycle Anthony Terriau

18-1. Retired, at last? The short-term impact of retirement on health status in France Thomas Barnay, Eric Defebvre 
17-11. Hiring discrimination against women: distinguishing taste based discrimination from statistical discrimination

Emmanuel Duguet, Loïc du Parquet, Pascale Petit

17-10. Pension reforms, older workers' employment and the role of job separation and finding rates in France

Sarah Le Duigou, Pierre-Jean Messe

17-9. Healthier when retiring earlier? Evidence from France

Pierre-Jean Messe, François-Charles Wolff

17-8. Revisting Hopenhayn and Nicolini's optimal unemployment insurance with job search monitoring and sanctions

Sebastien Menard, Solenne Tanguy

17-7. Ethnic Gaps in Educational Attainment and Labor-Market Outcomes: Evidence from France

Gabin Langevin, David Masclet, Fabien Moizeau, Emmanuel Peterle

17-6. Identifying preference-based discrimination in rental market: a field experiment in Paris

Mathieu Bunel, Yannick L’Horty, Loïc du Parquet, Pascale Petit

17-5. Chosen or Imposed? The location strategies of households

Emilie Arnoult, Florent Sari

17-4. Optimal income taxation with composition effects

Laurence Jacquet, Etienne Lehmann

17-3. Labor Market Effects of Urban Riots: an experimental assessment

Emmanuel Duguet, David Gray, Yannick L'Horty, Loic du Parquet, Pascale Petit

17-2. Does practicing literacy skills improve academic performance in first-year university students? Results from a randomized experiment

Estelle Bellity, Fabrices Gilles, Yannick L'Horty

17-1. Raising the take-up of social assistance benefits through a simple mailing: evidence from a French field experiment

Sylvain Chareyron, David Gray, Yannick L'Horty 
16-8. Endogenous wage rigidities, human capital accumulation and growth Ahmed Tritah

16-7. Harder, better, faster...yet stronger? Working conditions and self-declaration of chronic diseases

Eric Defebvre

16-6. The influence of mental health on job retention

Thomas Barnay, Eric Defebvre

16-5. The effects of breast cancer on individual labour market outcomes: an evaluation from an administrative panel

Thomas Barnay, Mohamed Ali Ben Halima, Emmanuel Duguet, Christine Le Clainche, Camille Regaert

16-4. Expectations, Loss Aversion, and Retirement Decisions in the Context of the 2009 Crisis in Europe

Nicolas Sirven, Thomas Barnay

16-3. How do product and labor market regulations affect aggregate employment, inequalities and job polarization? A general equilibrium approach

Julien Albertini, Jean-Olivier Hairault, François Langot, Thepthida Sopraseuth

16-2. Acces to employment with age and gender: results of a controlled experiment Laetitia Challe, Florent Fremigacci, François Langot, Yannick L'Horty, Loïc Du Parquet, Pascale Petit

16-1. An evaluation of the 1987 French Disabled Workers Act: Better paying than hiring

Thomas Barnay, Emmanuel Duguet, Christine Le Clainche, Yann Videau 
15-10. Optimal Income Taxation with Unemployment and Wage Responses: A Sufficient Statistics Approach

Kory Kroft, Kavan Kucko, Etienne Lehmann, Johannes Schmieder

15-9. Search frictions and (in) efficient vocational training over the life-cycle Arnaud Chéron, Anthony Terriau

15-8. Absenteeism and productivity: the experience rating applied to employer contributions to health insurance

Sébastien Ménard, Coralia Quintero Rojas

15-7. Take up of social assistance benefits: the case of homeless Sylvain Chareyron

15-6. Spatial mismatch through local public employment agencies. Answers from a French quasi-experiment

Mathieu Bunel, Elisabeth Tovar

15-5. Transmission of vocational skills at the end of career: horizon effect and technological or organisational change

Nathalie Greenan, Pierre-Jean Messe

15-4. Protecting biodiversity by developing bio-jobs: A multi-branch analysis with an application on French data

Jean De Beir, Céline Emond, Yannick L'Horty, Laetitia Tuffery

15-3. Profit-Sharing and Wages: An Empirical Analysis Using French Data Between 2000 and 2007

Noélie Delahaie, Richard Duhautois

15_2. A meta-regression analysis on intergenerational transmission of education: publication bias and genuine empirical effect

Nicolas Fleury, Fabrice Gilles

15_1. Why are there so many long-term unemployed in Paris?

Yannick L'Horty, Florent Sari 
14-14. Hiring discrimination based on national origin and the competition between employed and unemployed job seekers

Guillaume Pierné

14-13. Discrimination in Hiring: The curse of motorcycle women

Loïc Du Parquet, Emmanuel Duguet, Yannick L'Horty, Pascale Petit

14-12. Residential discrimination and the ethnic origin: An experimental assessment in the Paris suburbs

Emmanuel Duguet, Yannick L'Horty, Pascale Petit

14-11. Discrimination based on place of residence and access to employment Mathieu Bunel, Yannick L'Horty, Pascale Petit

14-10. Rural Electrification and Household Labor Supply: Evidence from Nigeria Claire Salmon, Jeremy Tanguy

14-9. Effects of immigration in frictional labor markets: theory and empirical evidence from EU countries

Eva Moreno-Galbis, Ahmed Tritah

14-8. Health, Work and Working Conditions: A Review of the European Economic Literature

Thomas Barnay

14-7. Labour mobility and the informal sector in Algeria: a cross-sectional comparison (2007-2012)

Philippe Adair, Youghourta Bellache

14-6. Does care to dependent elderly people living at home increase their mental health? Thomas Barnay, Sandrine Juin

14_5. The Effect of Non-Work Related Health Events on Career Outcomes: An Evaluation in the French Labor Market

Emmanuel Duguet, Christine le Clainche

14_4. Retirement intentions in the presence of technological change: Theory and evidence from France

Pierre-Jean Messe, Eva Moreno - Galbis, Francois-Charles Wolff

14_3. Why is Old Workers' Labor Market more Volatile? Unemployment Fluctuations over the Life-Cycle

Jean-Olivier Hairault, François Langot, Thepthida Sopraseuth

14_2. Participation, Recruitment Selection, and the Minimum Wage

Frédéric Gavrel

14_1. Disparities in taking sick leave between sectors of activity in France: a longitudinal analysis of administrative data

Thomas Barnay, Sandrine Juin, Renaud Legal 
13_9. An evaluation of the impact of industrial restructuring on individual human capital accumulation in France (1956-1993)

Nicolas Fleury, Fabrice Gilles

13_8. On the value of partial commitment for cooperative investment in buyer-supplier relationship

José de Sousa, Xavier Fairise

13-7. Search frictions, real wage rigidities and the optimal design of unemployment insurance

Julien Albertini, Xavier Fairise

13-6. Tax me if you can! Optimal non linear income tax between competing governments Etienne Lehmann, Laurent Simula, Alain Trannoy

13-5. Beyond the labour income tax wedge: The unemployment-reducing effect of tax progressivity

Etienne Lehmann, Claudio Lucifora, Simone Moriconi, Bruno Van Der Linden

13-4. Discrimination based on place of residence and access to employment

Mathieu Bunel, Emilia Ene Jones, Yannick L'Horty, Pascale Petit

12-3. The determinants of job access channels: evidence from the youth labor market in Franc

Jihan Ghrairi

13-2. Capital mobility, search unemployment and labor market policies: The case of minimum wages

Frédéric Gavrel

13-1. Effort and monetary incentives in Nonprofit et For-Profit Organizations Joseph Lanfranchi, Mathieu Narcy 
The CNRS Institute for Labor Studies and Public Policies (the TEPP Institute, FR n ${ }^{\circ} 3435$ CNRS) gathers together research centres specializing in economics and sociology:

- L'Equipe de Recherche sur l'Utilisation des Données Individuelles en lien avec la Théorie Economique (Research Team on Use of Individuals Data in connection with economic theory), ERUDITE, University of Paris-Est Créteil and University of ParisEst Marne-la-Vallée

- Le Centre d'Etudes des Politiques Economiques de l'université d'Evry (Research Centre focused on the analysis of economic policy and its foundations and implications), EPEE, University of Evry Val d'Essonne

- Le Centre Pierre Naville (Research on Work and Urban Policies), CPN, University of Evry Val d'Essonne

- Le Groupe d'Analyse des Itinéraires et des Niveaux Salariaux (Group on Analysis of Wage Levels and Trajectories), GAINS, University of the Maine

- Le Centre de Recherches en Economie et en Management, (Research centre in Economics and Management), CREM, University of Rennes 1 et University of Caen Basse-Normandie

- Le Groupe de Recherche ANgevin en Économie et Management (Angevin Research Group in Economics and Management), GRANEM, University of Angers ;

- Le Centre de Recherche en Economie et Droit (Research centre in Economics and Law) CRED, University of Paris II Panthéon-Assas ;

- Le Laboratoire d'Economie et de Management Nantes-Atlantique (Laboratory of Economics and Management of Nantes-Atlantique) LEMNA, University of Nantes ;

- Le Laboratoire interdisciplinaire d'étude du politique Hannah Arendt - Paris Est, LIPHA-PE

- Le Centre d'Economie et de Management de l'Océan Indien, «CEMOI», équipe d'accueil $n^{\circ} E A 13$, rattachée à l'Université de la Réunion

The TEPP Institute brings together 200 researchers and research professors and $140 \mathrm{PhD}$ students who study changes in work and employment in relation to the choices made by firms and analyse public policies using new evaluation methods. 